Synthesis, vol. 24 n 2, e022, diciembre2017. ISSN 1851-779X

Universidad Nacional de La Plata.

Facultad de Humanidades y Ciencias de la Educación.

Synthesis

Centro de Estudios Helénicos

\title{
Discurso e representação sobre as espartanas no período clássico
}

\author{
Fábio de Souza Lessa * \\ * Universidade Federal do Rio de Janeiro, Brasil \\ Luis Filipe Bantim de Assumpção* \\ * Universidade Federal do Rio de Janeiro, Brasil
}

Cita sugerida: de Souza Lessa, F. y Bantim de Assumpção, L. F. (2017). Discurso e representação sobre as espartanas no período clássico. Synthesis, 24 (2), e022. https://doi.org/10.24215/1851779Xe022 


\title{
Discurso e representação sobre as espartanas no período clássico
}

\author{
Fábio de Souza Lessa \\ Universidade Federal do Rio de Janeiro, Brasil \\ Luis Filipe Bantim de Assump̧̧ão \\ Universidade Federal do Rio de Janeiro, Brasil
}

\section{Resumo:}

A sociedade espartana adquiriu proeminência nas análises historiográficas que foram desenvolvidas, sobretudo, a partir do século XVIII. Dentre os mais variados elementos que compunham esta sociedade a figura da mulher espartana foi, sem dúvida, um aspecto amplamente debatido. As mulheres espartanas foram consideradas por duas perspectivas distintas: por vezes representadas pelo discurso dos autores clássicos como um modelo de conduta social; em outras ocasiões como dotadas de uma "liberdade" excessiva e práticas sexuais descomedidas. Desta maneira, objetivamos confrontar as imagens construídas por Xenofonte e Aristóteles, de modo a verificarmos as relações entre os seus respectivos discursos e o contexto social em que estes se encontravam no período clássico (séculos V e IV a.C.).

Palavras-chave: Espartanas, Gênero, Grécia clássica.

\section{Abstract:}

Spartan society has acquired prominence in historiographical analyses produced since the eighteenth century onwards. Among the various elements which composed this society the figure of the Spartan woman was undoubtedly a widely debated aspect. Spartan women were considered from two distinct perspectives: at times representedin the discourse of classical authors as a model of social conduct; on other occasions seen as having excessive 'freedom' and inordinate sexual practices. We aim to compare the images constructed by Xenophon and Aristotle to verify the relations between the respective discourses and the social context in the classical period (the fifth and fourth centuries BC).

KEYWORDS: Spartan women, Gender, Classical Greece.

\section{Mulheres espartanas: GÊNERo, Discurso E RePresentaÇÃo}

Na Hélade, Esparta foi objeto de elogios e críticas por políticos e pensadores que, em sua maioria, provinham do território ateniense. Se levarmos em consideração o contexto político-social que esses helenos vivenciavam -sobretudo, no período clássico- poderemos perceber os motivos pelos quais os lacedemônios foram considerados, no campo da documentação literária, ora como modelo de guerreiros e cidadãos, ora como o contraponto de uma sociedade ideal.

Mediante o discurso de Heródoto e de Tucídides verificamos que a ampliação do poder político e militar de Atenas, na primeira metade do século $\mathrm{V}$ a.C., teria levado ao embate com outras póleis, culminando na guerra do Peloponeso (431-404 a.C.). Por isso, os atenienses e os seus aliados passaram a enfrentar os membros da Confederação do Peloponeso, na disputa pela supremacia político-militar da Hélade. Com a vitória dos exércitos do Peloponeso, liderados pelos esparciatas, as oligarquias de diversos territórios helênicos passaram a considerar Esparta a pólis detentora da melhor forma de governo. Por sua vez, outros pensadores pontuaram que os lacedemônios nada tinham de grandioso em sua organização político-social. ${ }^{1}$

Desta maneira, após a guerra do Peloponeso, os discursos construídos pelos helenos fomentaram representações diversas das práticas políticas e sociais dos cidadãos da Lacedemônia. Sendo assim, os seus escritos alternavam entre a exaltação dos esparciatas e a desvalorizaçãodos elementos culturaisde Esparta.

Entre os diversos aspectos da sociedade lacedemônia que foram analisados e representados ainda na Antiguidade, percebemos as mulheres como um dos temas de maior recorrência e interesse dos autores do período clássico. Seja na documentação atribuída a Homero, nos pensamentos dos filósofos socráticos, nos 
teatros trágico e cômico, as mulheres de Esparta foram representadas como sinônimo de beleza e força, mas também como símbolo de avareza, descontrole social e descomedimento sexual. ${ }^{2}$

Ainda que as mulheres espartanas ${ }^{3}$ sejam o nosso enfoque de análise, iremos considerar a conjuntura histórica em que as mesmas se tornaram o objeto central de trabalhos acadêmicos. Isso nos fornecerá subsídios teóricos para observarmos, de modo alternativo, como foi representado o comportamento da mulher aristocrática de Esparta, em relação aos seus filhos e maridos, através da documentação literária da Antiguidade.

Teresa Meade e Merry Wiesner-Hanks (2004: 01) ressaltaram que os estudos sobre as mulheres ganharam maior importância no campo historiográfico através da visibilidade que os grupos femininos adquiriram no campo político mundial e das questões trazidas pelas discussões acerca da História de Gênero. Joan Scott (1992: 64-65), por já ter discutido questão semelhante, nos permitiu ampliar tal assertiva ao afirmar que por meio das modificações sofridas pelos "movimentos feministas", na segunda metade do século XX, os estudos sobre as mulheres puderam se afastar de um discurso que convergia com os pressupostos da "História Política Tradicional". ${ }^{4}$

Assim, pontuamos que as transformações pelas quais a História das Mulheres perpassou nos permitiu verificar a especificidade social que as mulheres - enquanto agentes históricos- detêm em uma sociedade. Do mesmo modo, destacamos que a História das Mulheres, além de garantir um lugar de fala às mulheres junto a um modelo de escrita histórica masculinizada, demonstrou que não podemos tentar compreendêlas como detentoras de um mesmo modo de pensar e agir. Portanto, enfatizamos que as análises históricas sobre as mulheres devem se manter atreladas aos seus respectivos contextos sociais, assim como ao grupo e ao território as quais pertencem.

No que concerne às mulheres na Antiguidade clássica, é relevante problematizar acerca da maneira como estas foram representadas no discurso literário. Em virtude das características oriundas do discurso documental, ressaltamos que a generalização das mulheres em uma categoria social única seria um mecanismo voltado para a legitimação de um conjunto de práticas político-culturais, em “sociedades masculinas". No que diz respeito às mulheres de Esparta, estas foram representadas em um contexto histórico específico para corresponder aos interesses que um autor gostaria de transmitir aos interlocutores de seu discurso.

$\mathrm{Na}$ contemporaneidade pensar a interação entre os grupos masculinos e femininos pressupóe inseri-los em uma dinâmica que os encare como relacionais. Tal relação é concebida como social e culturalmente construída. Estas premissas iniciais já nos colocam em sintonia com o conceito de gênero. Segundo Rachel Soihet (1997: 279), o próprio conceito "indica uma rejeição ao determinismo biológico implícito no uso de termos como 'sexo' ou 'diferença sexual”'. Assim, gênero se torna uma maneira de indicar a criação totalmente social das ideias acerca dos comportamentos próprios aos homens e às mulheres.

Reconhecendo que gênero é um dos objetos mais difíceis do estudo histórico, uma vez que é quase impossível de nos separarmos dele, pois implica em pensarmos as nossas identidades pessoais, Lin Foxhall (2013: 2) atenta para o fato de que a presença do elemento biológico no gênero - "masculino", "feminino" e seus corpos físicos-, significa que há algo relativamente fixo e compartilhado sobre o gênero ao longo da história humana.

O conceito de gênero aparece intimamente vinculado ao de poder. J. Scott (1995: 86; 1994: 20) já havia apontado para essa associação ao constatar que "o gênero é um elemento constitutivo das relações sociais baseadas nas diferenças percebidas entre os sexos" e ainda que "o gênero seja uma forma primária de dar significado às relações de poder". Assim sendo, gênero adquire a conotação de uma organização social da diferença sexual, baseada nos saberes, nas instituições, no poder e práticas produzidas pelas culturas sobre as relações entre homens e mulheres/masculino e feminino.

Embora não tenhamos a disposição uma diversidade documental sobre as mulheres espartanas do período clássico, verificamos que os locutores variaram em suas representações, as quais se restringiram a mulher proveniente da aristocracia, haja vista que esta poderia ser empregada como um ideal de conduta, por vezes 
voltado ao elogio das qualidades socioculturais de Esparta ou como o contraponto necessário para ratificar os valores da sociedade ateniense. Sendo assim, tornou-se necessária a aplicação teórica dos conceitos de discursos e representações no processo de construção da escrita da história.

Para elaborarmos o presente artigo utilizamos os textos de dois autores gregos de matrizes culturais atenienses, ou seja, Xenofonte e Aristóteles. ${ }^{5}$ Ao relacionarmos a obra desses autores antigos com a historiografia contemporânea, objetivamos compreender os discursos e representações elaborados sobre a mulher espartana. Logo, algumas considerações teóricas sobre o conceito de discurso e a sua relação com a representação mostram-se pertinentes a nossa proposta. Afinal, os indícios históricos oferecidos pela documentação literária são, na sua maioria, representações de um objeto discursivo de análise.

A partir dos estudos linguísticos desenvolvidos pela pesquisadora Eni Puccinelli Orlandi (1994: passim) conjeturamos que todo ato de comunicação desempenhado por seres humanos pode ser definido como uma forma de discurso. A autora informa que o discurso seria compreendido como um efeito de sentido que se estabelece entre locutores. No entanto, o discurso está diretamente vinculado à linguagem, e o modo como essa -enquanto função e atividade- permite que o sujeito se constitua e forneça sentido ao meio social em que vive, através da fala (Orlandi 1994: 53).

Discurso é entendido por Pierre Bourdieu (2009: 94) como o locus onde as relações interpessoais se desenvolvem, sobretudo pela utilização da fala. Desta maneira, por meio do discurso os segmentos sociais hegemônicos poderiam transmitir os seus valores e práticas, no seio de uma sociedade. De forma semelhante, o discurso seria o instrumento pelo qual os sujeitos constroem uma representação do meio em que vivem. Com essa imagem os homens representam os objetos, os grupos e os sujeitos com os quais convive visando interpretar e/ou explicar o seu meio social. Contudo, como nos chamou a atenção Bourdieu (2009: 46), as representações que se manifestam através do discurso não são neutras, e correspondem aos interesses dos grupos que as elaboram. Por meio das considerações teóricas apresentadas, acerca do discurso e a sua vinculação com a representação, podemos aplicar tal arcabouço em nosso estudo sobre a mulher de Esparta.

Ao adaptarmos as premissas de Eni Orlandi e Pierre Bourdieu para os estudos sobre Antiguidade, verificamos que o discurso de Xenofonte e Aristóteles estariam diretamente vinculados ao contexto histórico grego, do IV século a.C., bem como com o lugar que ocupavam na pólis de Atenas. Em linhas gerais, afirmamos que o discursode ambos os autores representouas práticas sociais da mulher espartana para que correspondessem aos seus respectivos interesses políticos. Logo, no intuito de podermos extrair um número maior de informações dos discursos presentes na documentação literária, recorremos ao contexto no qual tais autores produziram seus escritos, para que assim tenhamos maiores possibilidades em apreender a intenção de suas representações.

\section{As espartanas nas representaÇões discursivas de Xenofonte e de Aristóteles}

No que concerne às representações das espartanas, os discursos de Xenofonte e de Aristóteles se contrapõem em muitos aspectos. Enquanto Xenofonte exalta o comportamento e a organização política dos esparciatas de sua época em praticamente toda a sua Constituição dos Lacedemônios, Aristóteles, em especial na Política (II, 1269a-b), estabelece considerações que ressaltam as motivações que fariam da constituição de Esparta diferente daquela idealizada para uma pólis ideal. Em suas observações, Aristóteles enfatizou que o caráter militar a constituição de Esparta ocorreu devido ao seu amplo contingente de escravos hilotas, mas também pelo fato da Lacedemônia -região em que Esparta estaria localizada- estar rodeada de territórios inimigos.

Talvez sejam necessárias algumas considerações sobre os dois autores antes de analisarmos as suas obras. De acordo com John Lee (2017: 22-25), Xenofonte poderia ser entendido como um reflexo típico dos segmentos sociais abastados da sociedade ateniense do século $\mathrm{V}$ a.C. Afinal, fora um ávido atleta, um admirador da disciplina militar, dotado de ações políticas conservadoras, estritamente vinculado a tradição religiosa e perspicaz em suas abordagens. Já para Carlos García Gual (2010: 10), tornou-se habitual entre 
os pesquisadores modernos comparar o estilo de narrativa desenvolvido por Xenofonte com dois de seus contemporâneos, ou seja, Tucídides e Platão. Logo, através desse viés comparativo Xenofonte não seria detentor de um amplo rigor intelectual, e seus trabalhos careceriam de um fundo teórico-filosófico quando analisados em contraponto a Platão e Tucídides. Desta maneira, devemos entender Xenofonte de acordo com as suas especificidades, levando em consideração o seu lugar social e o seu comportamento frente à realidade histórica da Hélade, na passagem do V para o IV século a.C.

As afirmações de John Lee atrelam o comportamento de Xenofonte ao seu contexto social que pode nos fornecer indícios da sua trajetória de vida. Logo, o autor esteve submetido ao meio social no qual viveu, tal como nos expôs os seus próprios textos. No entanto, as ações que o autor tomou no decorrer de sua história não nos permite entender a sua trajetória de vida como linear e ordenada.

Cawkwell (1979: 9-10) nos informa que Xenofonte viveu numa Atenas devastada pela guerra, na qual os membros dos grupos abastados eram levados a gastar os seus recursos para a manutenção do conflito. Isso conduziu um típico membro do segmento social oligárquico a desenvolver um discurso que denunciasse as falhas e os excessos da participação do dêmos no poder político de sua pólis. Se considerarmos que Xenofonte foi adepto de uma oligarquia tradicional, as alusões às práticas democráticas seriam, na sua maioria, contrárias àquilo que acreditava em virtude das concepções do grupo ao qual pertencera. Com isso, o seu lugar social o fez construir uma representação de Esparta como um modelo ideal de sociedade, afinal, a "miragem" que se produziu dos costumes espartanos era a do êxito político e social por seguirem os valores ancestrais.

Com o fim da guerra do Peloponeso, Xenofonte ingressou no exército mercenário de Ciro "o jovem" e, posteriormente, mantido uma relação de amizade com o basileu Agesilau de Esparta. Teria sido esse seu vínculo com homens estrangeiros influentes - bem como inimigos de Atenas, na ocasião- que acarretou a perda de sua cidadania. Ao se retirar da Ática, Xenofonte se refugiou em Esparta e pouco depois recebeu dos lacedemônios uma propriedade em Escilunte -região situada a duas milhas de Olímpia, em Elis. Logo, o discurso presente na Constituição dos Lacedemônios teria a intenção de exaltar os elementos tradicionais e aristocráticos que constituíam a sociedade espartana, tomando como ponto basilar aquilo que o autor conheceu como modelo de organização política, ou seja, a pólis de Atenas. ${ }^{6}$

Por sua vez, Aristóteles provinha de Estagira, região de matriz cultural helênica na costa da Península Calcídica, na Macedônia. O contexto social de Aristóteles foi marcado por profundas modificações políticas, econômicas e culturais para a Hélade. Isto porque o século IV a.C. se diferenciou do seu predecessor pelo fato dos helenos estarem buscando respostas filosóficas para as questões que envolviam o sofrimento humano (Pomeroy 2004: 231). Imersos nessa lógica, a primeira metade do século IV a.C. para Atenas foi delimitada por suas transformações político-culturais seguidas de tentativas de se restabelecer a hegemonia política e econômica junto às póleis do Mar Egeu.

As perdas humanas e econômicas dos atenienses com a guerra do Peloponeso ainda se manifestavam no período seguinte, fazendo com que os pensadores do século IV desenvolvessem análises cujo enfoque seria discorrer sobre as melhores formas de se gerir uma pólis (Pomeroy 2004: 231-32), incluindo questões vinculadas aos grupos femininos. Contudo, a autoridade política e militar que os espartanos alcançaram com o final da guerra do Peloponeso não se estendeu por muito tempo. Em 371 a.C. os guerreiros esparciatas foram derrotados pelos tebanos na batalha de Leuctra (Rusch 2011: 194-99). Dessa forma, afirmamos que os autores que vivenciaram a desestruturação de Esparta após um período de supremacia sobre os helenos teceram críticas que enfatizassem os problemas de uma pólis pela desmedida das açóes de seus homens.

$\mathrm{Na}$ Politica, o estagirita discursou sobre a melhor forma de governo e a maneira como os homens deveriam exercer a sua autoridade sobre as mulheres, os filhos e os escravos. Ao estudar as instituições políticas vigentes na sociedade espartana de sua época, Aristóteles criticou eventos históricos que levaram os esparciatas ao enfraquecimento político, militar e social.

O discurso de Aristóteles foi diretamente influenciado por seu contexto histórico. Afinal, sendo um estrangeiro residindo em Atenas cabia ao mesmo ressaltar os excessos de Esparta, frente as tentativas 
atenienses de restabelecerem a sua autoridade política e econômica na Hélade. Entretanto, Paul Cartledge (2003: 216-17) declarou que Esparta resistiu à consolidação político-militar da Macedônia sobre a Hélade, na segunda metade do século IV a.C. Portanto, as críticas do estagirita foram pertinentes para o período no qual se encontrava, onde os esparciatas foram contrários à hegemonia política da Macedônia, da qual o filósofo seria um partidário. Do mesmo modo, as representações produzidas por Aristóteles acerca de Esparta enfatizaram que os esparciatas, ao abandonarem a tradição ancestral, foram incapazes de manter as conquistas que sucederam a guerra do Peloponeso. Assim, o lugar social de Aristóteles como um meteco na sociedade ateniense e como um defensor dos interesses da Macedônia influenciou a maneira como observou e representou a pólis espartana.

Aristóteles (Política, II, 1269 a-b) afirmou que o mítico legislador espartano Licurgo foi incapaz de controlar os interesses que as mulheres detinham pela riqueza e o seu descomedimento sexual.Desta maneira, o autor disforizou a imagem dos homens espartanos afirmando que estes, por serem provenientes de uma sociedade guerreira, eram dominados por suas mulheres. E ainda endossou o seu argumento ao citar a primeira invasão de Tebas a Lacedemônia, onde as mulheres aristocráticas de Esparta foram incapazes de reagir aos inimigos, causando confusão nos guerreiros esparciatas.

Anton Powell (2004: 140) afirmou que o ponto de vista de Aristóteles acerca das mulheres espartanas teria como finalidade refutar a ideia platônica de que Esparta seria um modelo de pólis ideal. Convergindo com Powell, Thomas Figueira (2010: 265-67) destaca que a ideia de uma ginecocracia (autoridade das mulheres) fora introduzida por Aristóteles como um meio de depreciar uma sociedade. Isso se deu pelo fato deste tipo de comportamento ser típico de sociedades consideradas como "bárbaras" pelos gregos. A partir dos apontamentos de Powell e de Figueira, defendemos que a representação da mulher espartana perpetuada na historiografia tradicional (entre o XIX até meados do XX) teve como uma de suas bases os escritos de Aristóteles. Tais estudos observaram o gênero feminino espartano como demasiadamente livre, ${ }^{7}$ ou então, analisaram tais mulheres como um contraponto ao modelo de mulher ideal, por vezes, representado pelas atenienses.

Oferecendo uma leitura alternativa dos textos literários, iremos contrapor o discurso de Xenofonte ao de Aristóteles, de tal maneira que visualizemos as informações provenientes dos escritos desses autores em conformidade com o contexto social no qual foram produzidos. Dessa maneira, seremos capazes de pontuar os possíveis anacronismos da historiografia produzida até então, no que concerne às mulheres de Esparta.

Retornamos a Xenofonte. Ao iniciar a sua obra ele nos informa que Licurgo conseguiu estabelecer a boa ordem (eunomía) entre os lacedemônios ao fazer vigorar a obediência às leis e à tradição espartana (Xenofonte. Constituição dos Lacedemônios 1.1). Dentre as determinações de Licurgo estava à maneira correta de como as jovens mulheres deveriam ser tratadas durante o período de gestação:

Sobre a procriação, por exemplo, começando pelo princípio, as demais (póleis) mantêm as jovens que vão dar à luz e que parecem bem educadas com uma comida a mais racionada e com menor condimento possível; mantêm-nas privadas de vinho ou servem-no aguado. Como a maioria dos artesãos que são sedentários, os demais gregos gostam que as jovens trabalhem a lã, levando uma vida inativa. (Xenofonte, Constituição dos Lacedemônios 1.3) ${ }^{9}$

O posicionamento do legislador espartano representado pelo discurso de Xenofonte enfatizou a importância que as mulheres de Esparta tinham para a sua sociedade. Portanto, os cuidados para com as mesmas eram fundamentais na tentativa de se desenvolver crianças fortes e robustas -sobretudo do sexo masculino. Contudo, a perspectiva de Aristóteles (Política II. 1269 b) se opõe a Xenofonte, vejamos:

A liberdade excessiva das mulheres é prejudicial ao fim do regime e à felicidade da cidade. [...] Foi o que sucedeu em Esparta. Desejando que a cidade fosse resistente, o legislador salvaguardou essa intenção no que se refere aos homens, mas foi negligente no que diz respeito às mulheres dado que estas vivem sem freio, entregues a toda a espécie de excessos e de indolência. ${ }^{10}$ 
$\mathrm{Na}$ visão aristotélica, Licurgo não teria conseguido alcançar o seu propósito em relação ao comportamento das mulheres, devido às tendências femininas aos desejos supérfluos. $\mathrm{O}$ posicionamento político de Aristóteles (Política I. 1253b) estaria fundamentado naquilo que considerou como natural na existência dos seres, haja vista a relação de dependência entre dois elementos onde um é dominante/superior e outro é dominado/inferior. Nesse caso o gênero feminino estaria sempre subordinado ao masculino, na ordem natural das coisas.

Ao que tudo indica, o pensamento de Aristóteles fazia parte da tradição ateniense de seu período, pois o filósofo complementou os seus estudos em Atenas. Com isso, propomos que devido ao contexto do século IV a.C., Aristóteles estaria expondo aos seus interlocutores uma representação de Esparta que justificaria os seus motivos por não considera-la um modelo de pólis ideal. Devido a este posicionamento, Aristóteles materializou o comportamento das espartanas como o contraponto das mulheres de Atenas, o que permite inferir que o treinamento recebido pelas mulheres em Esparta não detinha qualquer utilidade para a sua pólis.

Por sua vez, Xenofonte tenta fundamentar a sua opinião acerca da conduta das mulheres espartanas evidenciando as determinações de Licurgo para o sexo feminino. Nas palavras de Xenofonte (Constituição dos Lacedemônios 1.3), os "demais helenos" fazem com que as jovens se comportem de maneira sedentária, tal como os artesãos, e questiona se as mesmas poderiam fazer algo de grandioso levando uma vida inativa, somente trabalhando a lã. ${ }^{11}$ Ao analisarmos o discurso do ateniense notamos que o mesmo representou a mulher espartana de maneira singular quando comparada as de outras póleis. Em Xenofonte, as espartanas deveriam permanecer a maior parte de seu tempo alheias ao âmbito do lar, para que assim pudessem engendrar algo grandioso, ou seja, um jovem e futuro esparciata. Pomeroy (2002: 3) ressalta que em Esparta os jovens de ambos os sexos tinham um modelo educacional prescrito pela pólis, sendo da responsabilidade dos próprios espartanos vigiarem e organizarem o processo educacional poliade. O próprio Xenofonte endossa tal perspectiva ao declarar que:

Licurgo, por sua vez, pensou que as escravas bastavam para produzir vestidos e, como considerava que a procriação era a principal missão das mulheres livres, em primeiro lugar fez com que as mulheres exercitassem seus corpos não menos que os masculinos. Logo, organizou competiçôes para as mulheres, entre elas a corrida e provas de força, exatamente como fez com os varões, convencido de que matronas vigorosas também os filhos nascem robustos (Xenofonte, Constituição dos Lacedemônios $1.4)$.

Ao mencionar o modo de vida dos artesãos, Xenofonte efetuou uma crítica de caráter social e comparou o desenvolvimento de uma mulher criada ao ar livre com aquelas mantidas no interior do ôk kos. Defendemos a hipótese de que Xenofonte estaria projetando o comportamento tradicional dos homens de Esparta às mulheres, o que permitia que estas fossem consideradas superioras àquelas que permaneciam reclusas no interior da propriedade paterna ou de seu marido.

Não seria errôneo afirmar que Xenofonte fez uma crítica a educação recebida pelas mulheres de Atenas. Segundo Fábio Lessa (2004: 34), as tarefas femininas se resumiam à gerência da propriedade familiar, a habilidade de fiar, a confecção de vestuário, a tecelagem, a capacidade de transformar os cereais e a preparação do alimento, isto é, todas as atividades estritamente manuais. Tendo em vista o lugar social de Xenofonte entre os atenienses, entendemos que o autor estaria efetuando uma crítica mordaz, sobretudo, aos grupos sociais emergentes da pólis de Atenas. Porém, é necessário reforçar que as práticas dos exercícios físicos desenvolvidas pelas espartanas visavam ao cumprimento da principal função feminina para os gregos: a concepção de filhos legítimos. Neste aspecto, todas as mulheres gregas aparecem equiparadas. Pomeroy (2002: 4) afirma que a formação era prática e tinha objetivos claros, isto é, o desenvolvimento do tipo de mãe que a pólis precisava -no caso das mulheres-e dos guerreiros desejados pela sociedade -no que tange aos homens. No caso específico da educação feminina, era formar mães capazes de gerar guerreiros, ou seja, mães de hoplitai.

Tal perspectiva se caracterizou pelo fato destes sujeitos que, outrora, não detinham práticas tradicionais e não integravam as determinações políticas da pólis, terem adquirido "espaços de fala" com a emergência da 
democracia ateniense. Tendo em vista que Xenofonte foi um membro dos segmentos sociais abastados de Atenas, a sua censura teria sido direcionada aos grupos de matriz política democrática, por "romperem" com os valores da tradição aristocrática ateniense.

Ao analisar a Constituição dos Lacedemônios, Paul Cartledge declarou que a finalidade da mulher espartana era a de gerar filhos, para que estes dessem continuidade à linhagem familiar e fossem capazes de herdar a propriedade paterna. Contudo, Cartledge defende a ideia de que a mulher espartana não era versada nas técnicas de limpeza, na produção de roupas e na arte de cozinhar os alimentos, uma vez que estas tarefas eram direcionadas as escravas hilotas (2010: 78). O ponto de vista do autor pode ser endossado por Xenofonte (Constituição dos Lacedemônios 1.4) ao expor que em Esparta bastavam as mulheres escravas para efetuarem as atividades domésticas. Mas, sinceramente, não acreditamos que as espartanas não realizassem tais tarefas domésticas ou mesmo não tivessem o domínio de sua sophía.

Prosseguindo com a relação entre os discursos do período clássico, Aristóteles (Política II. 1269 b) admitiu que embora a mulher espartana fosse treinada de modo similar aos homens, isto não lhe servia de nada, pois as mesmas não iam para guerra.

Também no que se refere à bravura, que não é útil na vida corrente mas apenas em situação de guerra, as mulheres dos espartanos foram nefastas. Demonstraram isto no tempo da invasão tebana; ao contrário do que sucedeu noutras cidades, não foram nada úteis e causaram mais confusão do que o inimigo.

Dessa maneira, endossamos as premissas de Anton Powell e Thomas Figueira ao defenderem que na análise de Aristóteles, a educação proposta para o sexo feminino em Esparta não teria uma funcionalidade objetiva. Já Pomeroy (2002: 13-14) destaca que as evidências literárias demonstram que a atividade física das mulheres espartanas era semelhante àquela que os homens realizavam para a guerra. Neste caso, a utilidade prática do treinamento não existia, uma vez que as mulheres não iam à guerra. $\mathrm{O}$ estagirita se fundamentou na ideia da phýsis feminina que, por ser considerada inferior ao homem, impossibilitaria a esta de se comprometer com atividades distintas do seu caráter, tais como o treinamento militar. Entretanto, como observamos em Xenofonte, o treinamento físico pelo qual as espartanas deveriam perpassar não tinha finalidades guerreiras. Segundo Xenofonte (Constituição dos Lacedemônios 1.2-6), o legislador Licurgo instituiu o treinamento físico às mulheres de Esparta para que essas adquirissem a compleição física adequada para gerar guerreiros apropriados.

O discurso de Xenofonte também nos permite, em certa medida, romper com a visão aristotélica de que a constituição espartana era estritamente direcionada para a guerra. Essa perspectiva de Aristóteles foi influenciada por Platão e se fundamentou no contexto político-social de Esparta após a guerra do Peloponeso, onde os esparciatas passaram a se lançar, ao longo do Egeu, em embates com helenos e "bárbaros". De acordo com Xenofonte, embora este tenha enfatizado o treinamento militar dos espartanos, o seu objetivo principal foi a obediência que os cidadãos de Esparta tinham pela sua constituição, tornando-os não os melhores combatentes da Hélade, mas sim os melhores cidadãos existentes.

\section{Conclús̃̃o}

Por fim, a principal diferença que percebemos no discurso e na representação desenvolvida por Xenofonte e Aristóteles seria a autoridade que as mulheres exerciam na "pólis de Licurgo". Na Política (II. 1269b-1270a), Aristóteles defendeu a ideia de que os esparciatas, por se manterem demasiadamente ocupados com a vida militar, acabaram permitindo que as suas mulheres adquirissem influência sobre as determinaçóes políticas de Esparta. Tal argumento foi retomado por Paul Cartledge, no artigo intitulado "Spartan Wives: Liberation or License?”, no qual afirmou que Aristóteles expôs sete críticas a mulher aristocrática de Esparta.

Cartledge (2002: 131-38) mencionou que essas reprovações foram o motivo do enfraquecimento da sociedade espartana no século IV a.C., na visão aristotélica. Contudo, Thomas Figueira (2010: 268-69) 
declarou que Aristóteles se fundamentou em uma relação binária de oposição, entre o demos ateniense (representado pela população masculina) e a sociedade aristocrática espartana (que atribuía certa importância ao papel social da mulher). Por sua vez, Isabel Romeo (2006: 41) corrobora com os apontamentos de Figueira ao expor que a documentação literária nos fez chegar somente representações das mulheres espartanas, e não um posicionamento pessoal das mesmas em relação ao seu meio de vida.

De maneira distinta, Xenofonte apresentou aos seus interlocutores a importância que o mítico legislador Licurgo forneceu a todas as instâncias da sociedade de Esparta. Em linhas gerais, a representação que Xenofonte construiu dos esparciatas demonstrou como a constituição e as suas práticas político-culturais lhes garantiu a autoridade político-social da Lacedemônia durante séculos. Todavia, Xenofonte argumentou que uma sociedade que segue os valores da tradição obtém o sucesso, onde a interação de mulheres e homens garantiu a geração de guerreiros adequados para as finalidades políticas de Esparta. Com isso, o comportamento da mulher espartana seria diretamente proporcional às especificidades dos costumes desta sociedade, fator este que levaria a pessoas de outras póleis a considerarem-no como algo fora de um padrão adequado.

Sendo assim, concluímos que as representações das mulheres aristocratas de Esparta foram construídas através de uma comparação com as mulheres atenienses (seja em Xenofonte ou em Aristóteles). Mediante um viés alternativo, ainda que Aristóteles tenha criticado o comportamento das espartanas, estas eram o fruto de sua própria sociedade. O filósofo de Estagira (Politica II. 1269a - 1270a), no entanto, afirmou que seu objetivo não seria o de determinar o culpado pelos excessos dessa pólis, mas sim apontar os erros presentes na constituição vigente entre os habitantes de Esparta.

Por sua vez, notamos em Xenofonte (Constituição dos Lacedemônios 1.1 e 1.4) que a importância atribuída ao sexo feminino em Esparta, se vinculava a capacidade de gerar guerreiros para a pólis e devido ao número limitado de cidadãos do sexo masculino.

Com isso, observar a mulher como a "culpada" pela desestruturação do sistema político espartano, tendo como ponto basilar a obra de Aristóteles, poderia ser considerado um equívoco historiográfico. Ao tomarmos a proposta de certos historiadores modernos, quanto à "liberdade" da espartana, vemos que nenhum indivíduo era livre no interior da pólis de Licurgo, pois todos tinham de obedecer às determinações das leis e da tradição cultural. Todavia, salientamos que as especificidades culturais de Esparta deveriam ser analisadas dentro de seu próprio contexto político-social. Afinal, a importância das mulheres na sociedade espartana permitiu que estas adquirissem uma visibilidade que aos olhos dos atenienses foi tida como descomedimento do gênero feminino.

\section{Bibliografía}

Aristóteles (1998) Politica. Trad. A.C. Amaral e C. Gomes, Porto (Ed. Bilíngue).

Xenofonte (2002). A Constituição dos Lacedemônios. Trad. J. F. de Moura, en Costa, R. (org.). Testemunhos da História. Documentos de História Antiga e Medieval. Vitória: 35-66.

Bourdieu, P. (2009). O Senso Prático, Petrópolis.

Burke, P. (2005). O que é História Cultural?, Rio de Janeiro.

Cartledge, P. (2002). Spartan Wives: Liberation or License?, en M. Whitby (ed.), Sparta, Edinburgh: 131-138.

Cartledge, P. (2010). Termópilas - La batalla que cambió el mundo (Trad: David Léon y Joan Soler), Barcelona.

Cartledge, P. (2003). The Spartans - an Epic History, London: 216-217.

Cawkwell, G. (1979). "Introduction", en Xenophon: A History of my Times (Hellenica) (Trad. Rex Warner), London: $07-46$.

Cooper, J. (2003). “Aristotle”, en D. Sedley, (ed.). The Cambridge Companion to Greek and Roman Philosophy, Cambridge: $125-150$. 
Figueira, Th. (2010). "Gynecocracy: How Women Policed Masculine Behavior in Archaic and Classical Sparta”, en A. Powell \& S. Hodkinson (eds.) Sparta: The Body Politic, Swansea: 265-296.

Fornis, C. (2016). Esparta: la historia, el cosmos y la leyenda de los antiguos espartanos, Sevilla.

Gual, C. G. (2010). "Presentación”, en Jenofonte: Anábasis (Trad. Ramón Bach Pellicer), Madrid: 09-36.

Lee, J. W. I. (2017). "Xenophon and his Times", en M. Flower (ed.) The Cambridge Companion to Xenophon, Cambridge: $15-36$.

Lessa, F. S. (2004). O Feminino em Atenas, Rio de Janeiro.

Meade, T. A. \& Wiesner-Hanks, M. E. (2004). “Introduction”, en A Companion to Gender History, Oxford: 1-9.

Millender, E. (2009). “Athenian Ideology and the Empowered Spartan Woman”, en S. Hodkinson \& A. Powell (eds.) Sparta: New Perspectives, Swansea: 358-363.

Orlandi, E. P. (1994). “Discurso, Imaginário Social e Conhecimento”, Em Aberto 14. 61: 52-59.

Pomeroy, S. (2002). Spartan Women, Oxford.

Pomeroy, S. et alli (2004). A Brief History of Ancient Greece - Politics, History, and Culture, New York.

Powell, A. (2004). “The Women of Sparta -and of other Greek cities- at War”, en Th. Figueira (ed.), Spartan Society, Swansea: $137-150$.

Romeo, I. S. M. (2006). A Ambiguidade das Esposas Espartanas, Rio de Janeiro (Dissertação de Mestrado/UFRJ).

Rusch, S. (2011). Sparta at war: Strategy, Tactics, and Campaigns, 550-362 BC, London.

Scott, J. (1992). “História das Mulheres”, en P. Burke (org.) A Escrita da História: Novas Perspectivas, São Paulo: 63-95.

Scott, J. (1994). "Prefácio a Gender and Politics of History", Cadernos Pagu: desacordos, desamores e diferenças 3: 11-27.

Scott, J. (1995). "Gênero: uma categoria útil de análise histórica”, Educação \& Realidade 20. 2: 71-99.

Soihet, R. (1997). “História das Mulheres”, en C. F. Cardoso \& R. Vainfas (orgs.) Domínios da História: Ensaios de Teoria e Metodologia, Rio de Janeiro: 275-296.

Tigerstedt, E. N. (1965). The Legend of Sparta in Classical Antiquity I, Stockholm, Göteborg, Uppsala.

Vrissimtzis, N. (2002). Amor, Sexo e Casamento na Grécia Antiga, São Paulo.

\section{Notas}

1 Dentre os autores que euforizaram as práticas político-culturais de Esparta podemos destacar, em certa medida, Xenofonte (Helênicas, Constituição dos Lacedemônios) e Platão (República, Leis), cujos valores aristocráticos enfatizavam a importância da manutenção da tradição política em detrimento das inovações oriundas da democracia ateniense. Por sua vez, homens como Tucídides, Eurípides (Helena) e Aristófanes (Lisistrata) seriam típicos exemplos de pensadores que criticavam os costumes espartanos, por serem antiquados e não corresponderem aos interesses da Atenas democrática.

2 Na Ilíada e na Odisseia de Homero, Helena -rainha de Esparta- é vista como a mulher mais bela do mundo, e que seria detentora de uma grande influência e autoridade política. Por sua vez, nas peças de Eurípides, tais como Troianas, Andrôomaca, Orestes e Helena, a esposa de Menelau e sua filha Hermione são apresentadas como figuras autoritárias, controladoras, luxuriosas, tendo em vista a maneira como se comportavam diante de seus maridos (no caso de Hermione, também poderia se incluir Menelau, seu pai). Entre os filósofos socráticos, Platão tece afirmações que poderiam disforizar o comportamento feminino em Esparta, porém, pontua a existência de alguns elementos necessários para uma sociedade ideal, entre eles o fato da mulher ser um bem comum. O comediógrafo ateniense Aristófanes, principalmente nas peças Lisistrata e Thesmophoriazusae, aponta algumas das características das quais as espartanas seriam detentoras (Millender 2009: 358-63). No que tange aos escritos de Aristóteles e Xenofonte, os mesmos serão abordados no decorrer desse texto.

3 Esparta estava localizada na região da Lacedemônia, cuja extensão nos permite pontuar que havia uma pluralidade de grupos sociais e assentamentos humanos. No entanto, as representaçôes elaboradas pelos autores clássicos recaem sobre a mulher espartana, ou seja, filha e esposa de um esparciata, a qual pode ser identificada como oriunda da aristocracia. Do mesmo modo, existe na maioria dos casos um silêncio quanto às mulheres provenientes de outros grupos sociais lacedemônios (cf. Romeo 2006). 
4 Tal como nos esclareceu Peter Burke (2005: 17), a História Política tradicional foi hegemônica na Europa, pelo menos até a primeira metade do século XX, sendo o seu principal enfoque uma escrita de caráter oficial, voltada para os grandes homens e os seus grandes feitos na sociedade. Logo, podemos afirmar que era uma história eminente masculina.

5 Embora Aristóteles seja proveniente de Estagira, ele teria recebido a sua educação na "Academia de Platão", aspecto este que nos permite afirmar que a sua matriz cultural seja ateniense.

6 Cabe-nos ressaltar que no período em que Xenofonte viveu, a forma de governo que predominava entre os atenienses era a democracia. Como ressaltou Cawkwell (1979: 9), Xenofonte seria membro de uma antiga família aristocrática da Ática. Logo, exaltar as instituições de uma pólis como Esparta, era defender os valores de seu segmento social.

7 Podemos utilizar como exemplo a obra Sparta de Humphrey Michell, o livro História da Educação na Antiguidade de Henri-Irénée Marrou, ou até mesmo o texto de Elaine Fantham intitulado Spartan Women: Women in Warrior Society.

8 Ellen Millender (2009: passim) aborda essa construção da imagem espartana pautada na ideologia ateniense do período clássico. Todavia, Paul Cartledge (2010: 78) parece desenvolver seu ponto de vista estabelecendo uma comparação entre o comportamento da mulher ateniense e a maneira como as espartanas viviam em sua sociedade. Enquanto Nikos Vrissimtzis (2002: 33-39) apresenta a espartana como o oposto das atenienses.

Todas as citações da Política de Aristóteles foram traduzidas por Antônio C. Amaral e Carlos de Carvalho Gomes (1998).

9 Todas as citações da Constituição dos Lacedemônios de Xenofonte são de José Francisco de Moura (2002).

10 Todas as citações da Política de Aristóteles foram traduzidas por Antônio C. Amaral e Carlos de Carvalho Gomes (1998).

11 Na questão da educação, Sarah Pomeroy (2002: 3) destaca que diferente dos jovens, que eram recorrentemente examinados pelos adultos durante o seu processo de formação, as mulheres de boa estirpe deveriam ficar alheias aos olhos de terceiros. No entanto, essa visão é típica do caso ateniense, onde a jovem permaneceria no interior do ôkkos para aprender as habilidades necessárias a sua vida adulta. 